\title{
Thermal-Hydraulic Performance Analysis by Means of Rectangular Winglet Vortex Generators in a Channel: An Experimental Study
}

\author{
Oktarina Heriyani, Moh Djaeni, and Syaiful
}

\begin{abstract}
Vortex generators (VGs) are one of the effective passive models used to increase the heat transfer rate in heat exchangers. In this experiment, heat transfer from six cylinders heated to the airflow was improved by attaching rectangular winglet vortex generators (RWVGs) to a plate in a rectangular channel. The installation aimed to increase the value of the thermal-hydraulic performance evaluation criteria in the line. This experimental study was carried out by varying the fluid flow velocity from $0.4 \mathrm{~m} / \mathrm{s}$ to $2 \mathrm{~m} / \mathrm{s}$ with an interval of $0.2 \mathrm{~m} / \mathrm{s}$ in the channel. Three pairs of VGs were arranged in both in-line and staggered configurations. The experimental results show that the thermal-hydraulic performance evaluation criteria for three pairs of vortex generators in the staggered configuration was $15.17 \%$ higher than the baseline, while the thermalhydraulic performance of the in-line arrangement was $1.54 \%$ higher than the staggered one.
\end{abstract}

Index Terms - performance, thermal, rectangular winglet, vortex, in-line, staggered.

\section{INTRODUCTION}

The use of household and industrial air conditioning is increasing. Therefore, improving thermal-hydraulic performance of air conditioning components is of concern to researchers. The passive method (using a vortex generator) is an effective way to improve the hydraulic thermal performance of heat exchangers. Samadifar et al. studied the numerical effects of VGs on thermal hydraulic performance in plate fin heat exchangers [1] and found that using rectangular VGs on the fin plate resulted in maximum thermal-hydraulic performance. According to a study by $\mathrm{Z}$. Han et al. the shapes of VGs, such as modified rectangular winglet vortex generators (RWVGs), also influence thermalhydraulic performance [2]. H. Ling Liu et al. modified the heights of the RWVGs [3], while H. Naik et al. used modified RWVGs with concave shapes to improve thermal-hydraulic performance [4].

Concave RWVGs' surfaces, according to the findings of Y. Wang et al. give rise to longitudinal vortices [5] which impact thermal-hydraulic performance. Investigations by Liu et al. [6] concluded that this new vortex generator (VG) geometry can improve thermal-hydraulic performance. Likewise, the findings of Modi et al. show that wavy up and wavy down winglet VGs with a common flow down (CFD) configuration can improve thermal-hydraulic performance [7]. The results of a study by C. Zhai et al. showed that the

Submitted on April 08, 2021.

Published on April 29, 2021.

Oktarina Heriyani

(e-mail: oktarina@uhamka.ac.id) thermal-hydraulic performance of the delta winglet vortex generator (DWVG) pair with a CFD configuration is better than common flow up (CFU) [8] because the vortices formed from a pair of winglets create a downwash flow toward the wall between the vortex and the two upwash flows in the outer region of the vortex in the CFD configuration.

The optimal VG configuration for improved thermalhydraulic performance was explored by J. Xie and Lee at a height ratio of 0.8 and a radius ratio of 1.55 , with the obtained performance evaluation criterion (PEC) ranging from 1.3 to 1.5 times [9]. The increase in PEC can reach $34 \%$ based on the results of the study of A. Gupta et al. [10]. Their results were achieved using the RWVG perforated and CFU configuration at the upstream location. The thermal-hydraulic performance of the heat exchanger is also influenced by the placement and arrangement of VGs, which was demonstrated in research conducted by $\mathrm{H}$. Naik et al. [11]. Their findings show that RWVG pairs in a staggered arrangement improved thermal-hydraulic performance better than those in an in-line arrangement. H. Naik et al. analyzed the thermodynamic performance of a fin tube heat exchanger arranged in-line by adding three pairs of RWVGs [12]. The results of their analysis show that the location of the RWVGs' paired arrangement affects thermal-hydraulic performance.

Given the findings discussed above, the experiments carried out in this study investigated the effects on thermalhydraulic performance of three pairs of RWVGs arranged inline and staggered on the plate in the channel based on the ratio of the Colburn factor $(j)$ to the friction factor $(f)$.

\section{Methodology}

This research was conducted experimentally in the thermofluid laboratory of the Department of Mechanical Engineering, Diponegoro University. This experiment used a rectangular air duct with dimensions of $370 \times 18 \times 8 \mathrm{~cm}$. The channel was made of glass, equipped with a blower, hot wire anemometer, pitot tube, straightener, micromanometer (fluke), heater, watt meter, type $\mathrm{K}$ thermocouple, heating plate, data acquisition, and regulator, as shown in Fig. 1 below.
Moh Djaeni

(e-mail: moh.djaeni@ ${ }^{1}$ live.undip.ac.id)

Syaiful

(e-mail: syaiful.undip2011@gmail.com). 


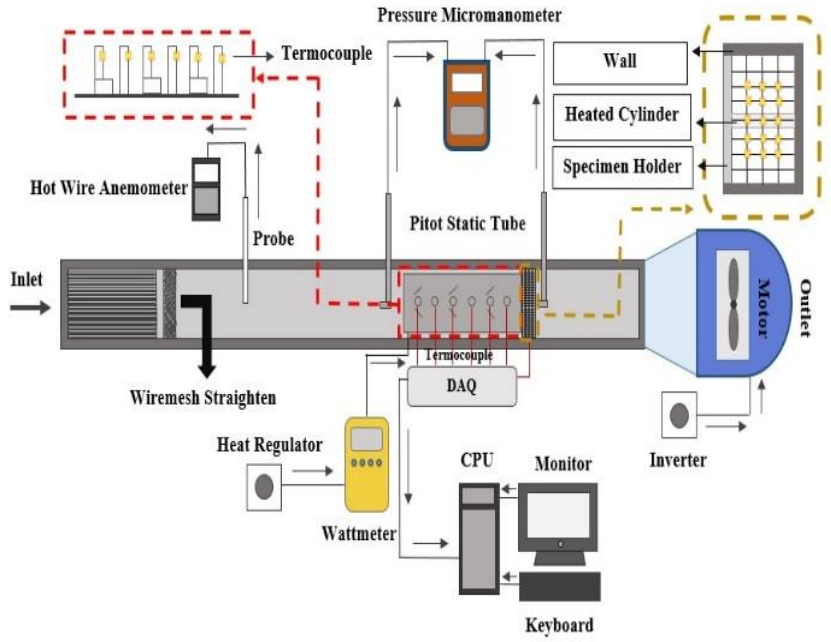

Fig. 1. Specimens of the test equipment.

Tests in this experiment varied the intake air velocity from $0.4 \mathrm{~m} / \mathrm{s}$ to $2 \mathrm{~m} / \mathrm{s}$ with an interval of $0.2 \mathrm{~m} / \mathrm{s}$. Then, the air flowed through six cylindrical tubes, each with a diameter of $19.05 \mathrm{~mm}$ and a height of $65.8 \mathrm{~mm}$. Six rows of cylinders were installed in-line, each with a diameter of $19.05 \mathrm{~mm}$ and a length of $65.8 \mathrm{~mm}$. The distance between the cylinders was $60 \mathrm{~mm}$, with a fixed angle of attack of $15^{\circ}$. The results of $\mathrm{Lu}$ and Zhai's observations showed that the best thermalhydraulic performance was at an angle of attack of $15^{\circ}$ [6].

The RWVGs used in this experiment had dimensions of $30 \times 30 \mathrm{~mm}$. The RWVGs were mounted on aluminum plates, which were $500 \mathrm{~mm}$ long, $155 \mathrm{~mm}$ wide, and $1 \mathrm{~mm}$ thick. The RWVGs were installed on the plates, both in-line and staggered (Fig. 2a, b, c, and d).

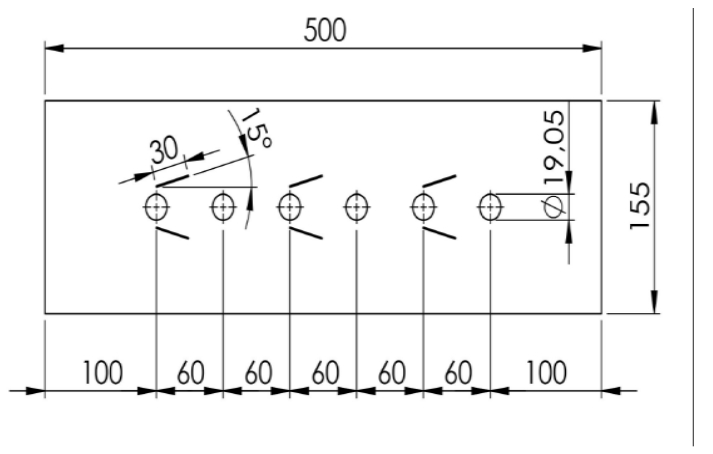

(a)

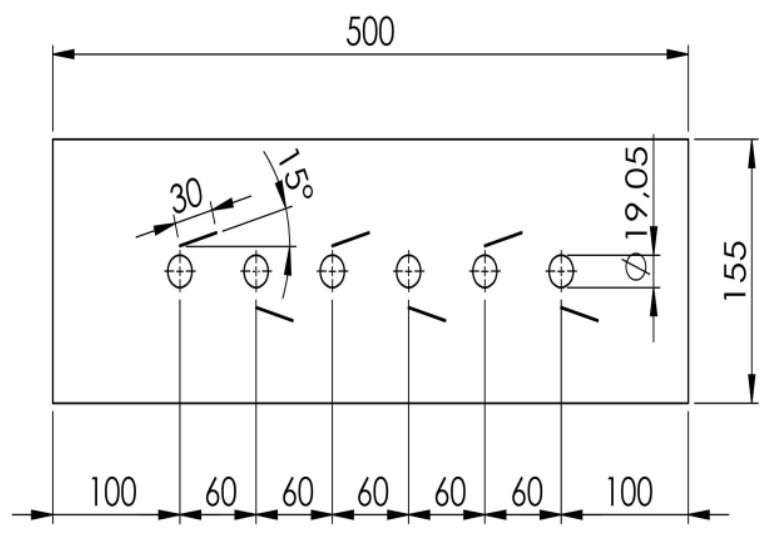

(b)

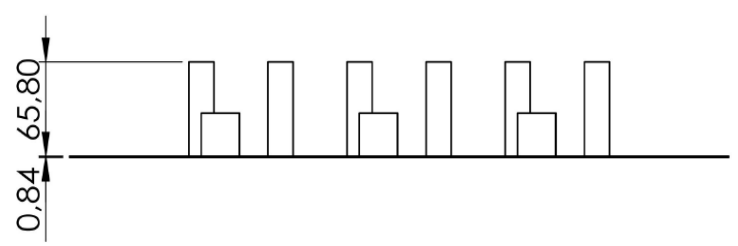

(c)

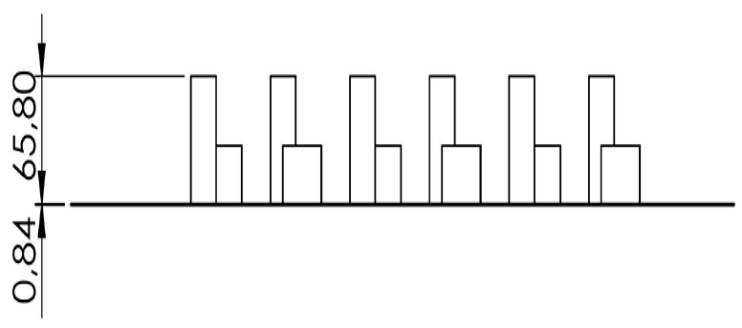

(d)

Fig 2. Test specimens:

(a) Top plane of RWVGs arranged in three in-line rows;

(b) Top plane of RWVGs arranged in three staggered rows;

(c) Side plane of RWVGs arranged in three in-line rows;

(d) Side plane of RWVGs arranged in three in-line rows.

The data obtained from the experiment were calculated based on the ratio of the Colburn factor $(j)$ to the friction factor $(f)$ to obtain the thermal-hydraulic performance (PEC) with the following formulas:

$$
j=\frac{N u}{\operatorname{Re} \cdot \operatorname{Pr}^{\frac{1}{3}}}
$$

where $j$ is the Colburn factor, and

$f=\frac{2 \Delta_{p} D_{h}}{\rho u_{i n} L}$

where $\mathrm{f}$ is the friction factor. Therefore,

$$
P E C=\frac{\frac{j_{1}}{j_{0}}}{\left(\frac{f_{1}}{f_{0}}\right)^{\frac{1}{3}}}
$$

\section{RESULTS AND DISCUSSION}

The effects of the RWVGs on thermal-hydraulic performance were studied by comparing the baseline PEC to the PEC when arranged in-line and staggered, with the addition of three pairs of RWVGs in a rectangular channel passing through six heated cylinders. The discussion of PEC is based on the JF factor, which is the ratio between the Colburn factor and the friction factor, which is formulated in (3).

Fig 3 shows the effects of the aforementioned arrangements on the Colburn factor. According to Modi et al., a decrease in the Colburn factor entails an increase in the Reynolds (Re) number [7]. 


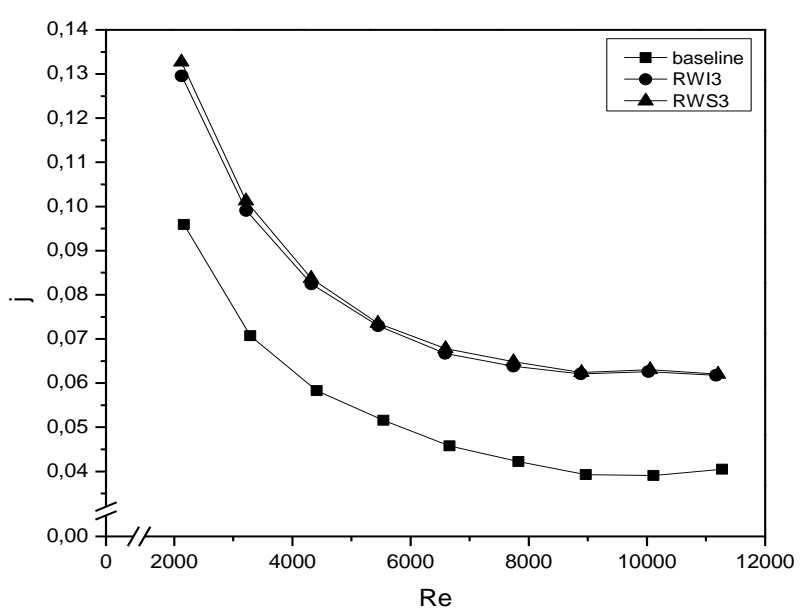

Fig 3. Graph of $\mathrm{j}$ values versus Re for in-line and staggered arrangements

Fig. 3 shows a decrease in the Colburn factor (j) and an increase in the Re number in the RWVGs with in-line and staggered arrangements. The highest Colburn factor $(j)$ value (0.13) at a low Re number was found in staggered RWVG arrangements. The lowest Colburn factor value (0.0618) was found in in-line RWVGs arrangements. This is due to the influence of the main vortices induced by the fluid flow downstream of the RWVGs. Therefore, based on experimental data, the arrangements of paired VGs' row configurations affect the resulting Colburn factor $(j)$ values [13].

The determination of the PEC is influenced not only by the Colburn factor, but also by the friction factor $(f)$. The friction factor decreases as the Re number increases, according to the findings of Modi et al [7]. However, a higher variation of the Re number is found to be nearly constant in their $f$ value according to their analysis. This is due to reducing the coefficient of resistance.

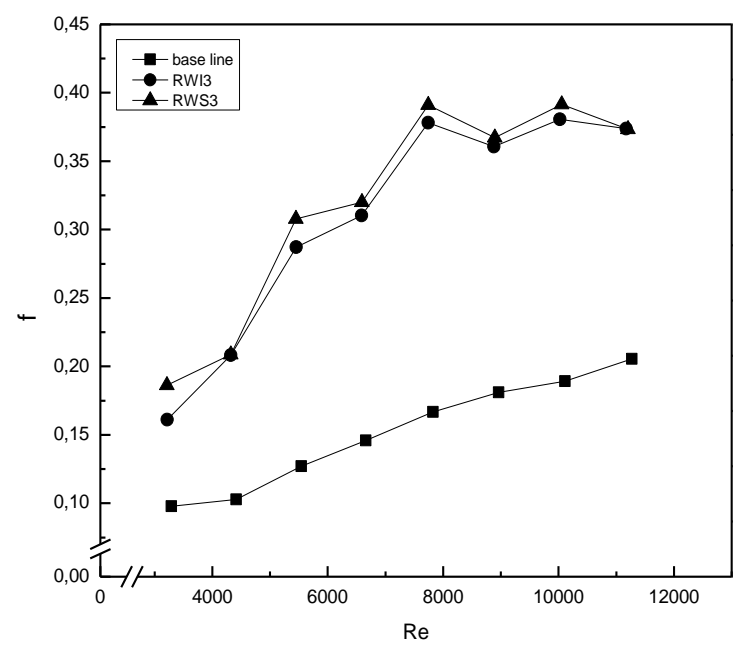

Fig. 4. Graph of $f$ values versus Re.

Fig. 4 shows that the value of the friction factor (f) was higher in the staggered arrangement than in the in-line arrangement [14]. The highest value of friction factor (f) was in the staggered arrangements (0.392), and for the three inline row arrangements, it was 0.381 . The number of rows affects the value of the friction factor (f); the more rows there are, the greater the value of the friction factor (f) [4].

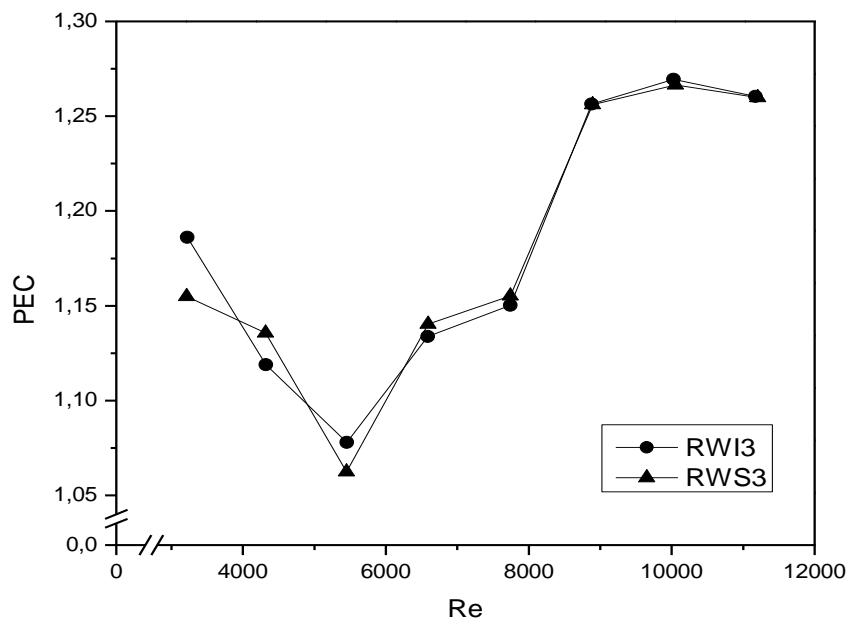

Fig. 5. Graph of PEC values versus Re.

The variation in the PEC value generated with $\mathrm{Re}$, as shown in Fig 5, explains the effect of the JF factor ratio and the friction factor on the increase in the PEC value, which is in line with the increase in $\operatorname{Re}[10]$. The resulting PEC values were larger in RWVGs with staggered arrangements than in those with in-line arrangements. The number of rows also affects PEC values; the more RWVG rows there are, the greater the resulting PEC value, which is caused by flow resistance [2]. The PEC as a performance evaluation scale in this experiment gave the best indication by the ratio between the number of rows of in-line and staggered installations of RWVGs. The largest PEC value (1.27) was in the staggered RWVG arrangement with three pairs.

\section{CONCLUSION}

The effects of RWVGs on the performance evaluation criterion in heat exchanger tubes were determined by comparing the results of in-line and staggered arrangements. Overall performance was based on the JF factor by calculating the ratio of the Colburn factor $\left(\mathrm{j}_{1} / \mathrm{j}_{0}\right)$ to the friction factor $\left(f_{1} / f_{0}\right)^{1 / 3}$. The effect of thermal characteristics and pressure drop can be seen from the JF factor obtained.

The staggered arrangement showed an increase in the PEC value proportional to the increase in the Colburn factor for the increase in $\mathrm{Re}$ number and inlet velocity by $15.17 \%$ compared to the baseline and $1.54 \%$ lower than the in-line arrangement with three rows. Therefore, the staggered arrangement of RWVGs and a greater number of rows increase the PEC value.

\section{ACKNOWLEDGMENT}

Thanks to the UNDIP Thermofluid Laboratory for providing a place to conduct data collection experiments and UHAMKA, which helped to finance this experiment in the research scheme.

\section{REFERENCES}

[1] M. Samadifar and D. Toghraie, "Numerical simulation of heat transfer enhancement in a plate-fin heat exchanger using a new type of vortex generators," Appl. Therm. Eng., vol. 133, no. September 2017, pp. 671681, 2018, doi: 10.1016/j.applthermaleng.2018.01.062.

[2] Z. Han, Z. Xu, and J. Wang, "Numerical simulation on heat transfer 
characteristics of rectangular vortex generators with a hole," Int. J. Heat Mass Transf., vol. 126, pp. 993-1001, 2018, doi: 10.1016/j.ijheatmasstransfer.2018.06.081.

[3] H. ling Liu, H. Li, Y. ling He, and Z. tao Chen, "Heat transfer and flow characteristics in a circular tube fitted with rectangular winglet vortex generators," Int. J. Heat Mass Transf., vol. 126, 2018, doi: 10.1016/j.ijheatmasstransfer.2018.05.038.

[4] H. Naik, S. Harikrishnan, and S. Tiwari, "Numerical investigations on heat transfer characteristics of curved rectangular winglet placed in a channel," Int. J. Therm. Sci., vol. 129, no. April, pp. 489-503, 2018 , doi: 10.1016/j.ijthermalsci.2018.03.028

[5] Y. Wang, P. Liu, F. Shan, Z. Liu, and W. Liu, "Effect of longitudinal vortex generator on the heat transfer enhancement of a circular tube," Appl. Therm. Eng., vol. 148, no. May 2018, pp. 1018-1028, 2019, doi: 10.1016/j.applthermaleng.2018.11.080.

[6] G. Lu and X. Zhai, "Effects of curved vortex generators on the air-side performance of fin-and-tube heat exchangers," Int. J. Therm. Sci., vol. 136, no. May 2018, pp. 509-518, 2019, doi: 10.1016/j.ijthermalsci.2018.11.009.

[7] A. J. Modi, N. A. Kalel, and M. K. Rathod, "Thermal performance augmentation of fin-and-tube heat exchanger using rectangular winglet vortex generators having circular punched holes," Int. J. Heat Mass Transf., 2020, doi: 10.1016/j.ijheatmasstransfer.2020.119724.

[8] C. Zhai, M. D. Islam, M. M. Alam, R. Simmons, and I. Barsoum, "Parametric study of major factors affecting heat transfer enhancement in a circular tube with vortex generator pairs," Appl. Therm. Eng., vol. 153, no. March, pp. 330-340, 2019, doi: 10.1016/j.applthermaleng.2019.03.018.

[9] J. Xie and H. M. Lee, "Flow and heat transfer performances of directly printed curved-rectangular vortex generators in a compact fin-tube heat exchanger," Appl. Therm. Eng., 2020, doi: 10.1016/j.applthermaleng.2020.115830.

[10] A. Gupta, A. Roy, S. Gupta, and M. Gupta, "Numerical investigation towards implementation of punched winglet as vortex generator for performance improvement of a fin-and-tube heat exchanger," Int. J. Heat Mass Transf., 2020, doi: 10.1016/j.ijheatmasstransfer.2019.119171.

[11] N. Heman and T. Shaligram, "Thermal performance analysis of fintube heat exchanger with staggered tube arrangement in presence of rectangular winglet pairs," Int. J. Therm. Sci., 2020.

[12] H. Naik and S. Tiwari, "Thermodynamic performance analysis of an inline fin-tube heat exchanger in presence of rectangular winglet pairs,' Int. J. Mech. Sci., 2021, doi: 10.1016/j.ijmecsci.2020.106148.

[13] W. M. Yan and P. J. Sheen, "Heat transfer and friction characteristics of fin-and-tube heat exchangers," Int. J. Heat Mass Transf., 2000, doi 10.1016/S0017-9310(99)00229-X.

[14] Y. H. Zhang, X. Wu, L. B. Wang, K. W. Song, Y. X. Dong, and S. Liu, "Comparison of heat transfer performance of tube bank fin with mounted vortex generators to tube bank fin with punched vortex generators," Exp. Therm. Fluid Sci., 2008, doi: 10.1016/j.expthermflusci.2008.07.002.

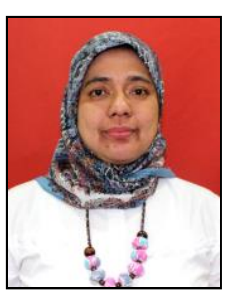

Oktarina Heriyani was born in Palembang on June 5, 1977. Her last education was Master of Engineering (M.T) majoring in Industrial Engineering and Management, Institute of Technology Bandung in 2003. Currently, She is currently studying for a Doctoral Program in Mechanical Engineering Study Program at Diponegoro University, Semarang, Indonesia.

The author is a lecturer at the Faculty of Engineering, Prof. Dr. HAMKA which is located in East Jakarta, Indonesia. Some of the author's publications in recent years include the effect of vortex generator on the approach value on forced draft type cooling tower, effect of cylinder surface roughness to the distance formation of vortex, and performance improvement of a forced draughat cooling tower using a vortex generator.

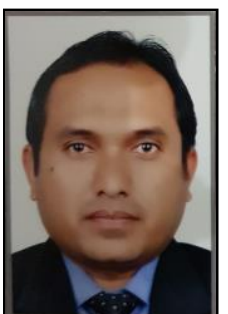

Syaiful was born on March 8, 1974 in Malang. Ph.D in Mechanical and Aerospace Engineering, Gyeongsang National University, Korea, M.Eng., Mechanical Engineering, Institute Technology of Bandung, Indonesia and B.Eng., Mechanical Engineering, University of Brawijaya, Indonesia $\mathrm{He}$ is a lecturer, mechanical engineering, Diponegoro University, Indonesia with the teaching area of engineering mathematics, internal combustion engine, numerical analysis, and computational fluid dynamics. His publications include numerical analysis of heat and fluid flow characteristics of airflow inside rectangular channel with presence of perforated concave delta winglet vortex generators, effect of butanol on performance and smoke emission of direct injection diesel engine fueled bby jatropha oil and diesel fuel with egr system, and thermo-hydrodynamics performance analysis of fluid flow through concave delta winglet vortex generators by numerical simulation. His research interest is in the field of development of new selective catalytic reduction devices for reducing nox and soot emissions from diesel combustors, development of renewable energy sources, thermofluid (heat transfer and fluid mechanics)

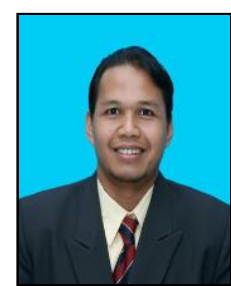

Mohamad Djaeni, born on February 7, 1971. Master of Engineering at Universiti Teknologi Malaysia, Malaysia. Doctoral system and control group at Wageningen University, Netherlands.

$\mathrm{He}$ is a Professor at Diponegoro University, Semarang, Indonesia. Some of his publications, air dehumidification with advance adsoptive materials for food drying: a critical assessment for future prospesctive, a kinetic study on color degradation during application of dried colorant from roselle extract with foaming agent, and optimization foam mat drying of roselle (Hibiscus sadariffa L.) extract. 